\title{
Investigating factors affecting feasibility study of construction projects in Iraq
}

\author{
Mohammed Neamah Ahmed ${ }^{1}$, Hussein Ali Mohammed ${ }^{2}$, Gafel Kareem Aswed ${ }^{3}$, Wajde S. S. Alyhya ${ }^{4}$ \\ ${ }_{1,2,3,4}$ Departement of Civil Engineering, University of kerbala
}

\section{Article Info}

Received January 14, 2019

Keyword:
Construction Projects
Feasibility Study
AHP
Relative Importance Index
Economic Feasibility

\begin{abstract}
The views at the construction field emboss that construction parties are looking for a higher benefit during implementing aspects of any project. The feasibility study is one of the serious and significant matters in construction sectors as well as in other engineering fields as it has a high impact on investment decision-making. To gain rigorous decisions from decision-makers or contractual parties (client, consultant, and contractor), there is a need for valuable feasibility studies in any construction project. This paper aims to study the influence of some identified factors on feasibility studies as well as the extents of priorities of various feasibility studies. In this paper, the critical factors that have an impact on sequences of initial feasibility studies during the lifecycle of a construction project were identified as well as the associated studies (legal, environment, marketing, technical, managerial, schedule, financial and economic). In this study, 12 factors were identified, analyzed, and thoroughly discussed to have recommendations of their impact on initial feasibility in construction projects in Iraq via a questionnaire survey and a series of expert interviews conducted in Iraq. The Analytical Hierarchy Process (AHP) as a multi-criteria decision support system was adopted to examine the weight of each factor. In addition, an analysis by the Relative Importance Index (RII) was carried out to rank eight types of feasibility studies in terms of their perceived importance. The results of AHP indicated that the local shortage of database about the feasibility study was the most critical factor. Indeed, RII's result showed that all kinds of feasibility for construction projects in Iraq are not adopted by the client. In fact, the economic feasibility study was the most popular than others.
\end{abstract}

\section{Corresponding Author:}

Mohammed Neamah Ahmed, Departement of Civil Engineering, University of Kerbala, Iraq

Email: mohammed.niema@uokerbala.edu.iq

\section{Introduction}

Feasibility analysis is a detailed study of how a project can be completed and accounting for factors that might affect it such as technological, economic, legal and scheduling factors [1]. Feasibility analysis allows determining and organizing all the necessary details to produce successful business work [2]. It has become one of the most important tools for strategic planning nowadays. Moreover, feasibility analysis considers as an effective methodology for the strategic management of projects in various investment and economic activities, which lead to the investment decision-making over the project' whole life with the least possible degree of uncertainty (risk) [3]. The feasibility analysis has been generated from the economic theory core to support 
investment decision-making under a certain degree of risk and/or uncertainty and stemmed from the existence of many internal and external variables concerning with the future that might affect decisions [4-5].

Generally, the word "feasibility study" is an expression in the accounting and economic sciences that appeared in the early sixties to simply define precise examinations and reviews to determine the feasibility of different investment alternatives by calculating benefits and costs to extract measurements for every alternative [6]. The outcome of the feasibility study helps in selecting a defined project that meets the stated objectives of project, together with a broad plan of implementation [7-8]. A real estate project is feasible when the real estate analyst determines that there is a reasonable likelihood of satisfying explicit objectives when a selected course of action is tested for fit to a context of specific constraints and limited resources [9]. In this paper, the following studies represent the frameworks of the dimensions of business viability: (market, economic, financial, technical, environmental, legal, schedule, and managerial). Those studies represent the main types of feasibility study, which are necessary for any business frames [10-11]. In any construction sequence, there are many factors associated with many concepts [12] that may create many negative impacts [13]. These factors are posted different levels of impacts (down or up) on an initial feasibility study in systematic construction sector [14-15].

The governments' funds may cover more than $96 \%$ of the local construction projects in Iraq. The funds for construction projects make the central and local governments need to more control on all sequences of the local projects. There are numerous issues that had generated various factors that affect and associate with projects feasibilities such as bad management planning, misunderstanding projects objectives, lack of commitments from top management and extra other factors. These factors may have highly impacts on sequences of construction projects lifecycle, which will increase the costs, minimize the long-term benefits from projects and other issues. In addition, our technical libraries are suffering from a shortage of information about the feasibility studies that related to construction sectors. Hence, this study aims to identify the factors affecting initial feasibility study in an Iraqi construction project and to make the analysis and re-arrangement of those factors based on the analysis aspect to show the level of their effects.

\section{Research Methodology}

In the first stage, secondary data has been gathered from various sources through qualitative data collection techniques. The adopted data has been utilized for the development of a questionnaire. In the second stage, primary data has been collected from a questionnaire survey, through quantitative data collection technique. In this regard, an opinion of consultants, experienced engineers, specialist engineer, and project managers in the construction sector has been gathered to obtain a wider perspective and to have a very close study to the situation of fieldwork in Iraq. The gathered information was finally used to explore the perception of Iraqi construction industry regarding the feasibility studies. The minor and major sections in the designed questionnaire format were illustrated the targeted groups from the people have significant linked and direct contact with the feasibility study and they demonstrated their different knowledge and views.

\section{Contains and Description of Questionnaire Format}

The intended questionnaire indicates to major and minor collection data. The major section consists of 12 targeted factors associated with an initial feasibility study in the context of Iraq. The listed factors are collected through experienced engineers, consultants, and surveys from other studies. The details of the important factors affecting the feasibility studies with respect to different countries are defined in Table 1. On the other hand, the minor section consists of views from the targeted people about which one of the feasibility studies almost prepared in their works. The minor section includes the views of targeted peoples about if (use or non-use) of the types of feasibility study and extra.

The answers were to be according to the field knowledge and wide experiences and not belong to any particular construction or engineering project. Through looking at the questionnaire, it was easy to understand and no confused inside its format. 
Table 1. List of factors

\begin{tabular}{ll}
\hline Sr. & List of The factors \\
\hline 1 & Misunderstanding objectives of projects (F1) \\
2 & Shortage of experience and field knowledge (F2) \\
3 & Shortage of fund (F3) \\
4 & Shortage of Database about feasibility study locally (F4) \\
5 & Shortage of period during the conceptual phase (F5) \\
6 & Mess and Lack of planning (F6) \\
7 & Lack of Decision Making from Top Management (F7) \\
8 & Misunderstanding regulation and client's requirements (F8) \\
9 & Misunderstanding of stages and sequences Feasibility Study (F9) \\
10 & Lack of commitments and Liabilities (F10) \\
11 & Lack of understanding the risks associated with the project (F11) \\
12 & Misunderstanding in the classification of project costs (F12) \\
\hline
\end{tabular}

\section{Method of Analysis and Results}

The 70 questionnaire forms have been distributed to the targeted technical groups. Those groups have a wide technical knowledge and experiences in designing and execution construction projects. The correct forms, which had been received from those groups were 59 questionnaires forms. The remaining 11 forms were incorrect and they were neglected from the final analysis basis. The statistical analysis process was done by highlighting the responses based on the questionnaire formats into the following categorizations.

\subsection{The Pivot of Results for First Section}

This section includes the main personal and technical information. Figs. 1, 2 and 3 use for showing and representing the distribution data in the pivot of this section.

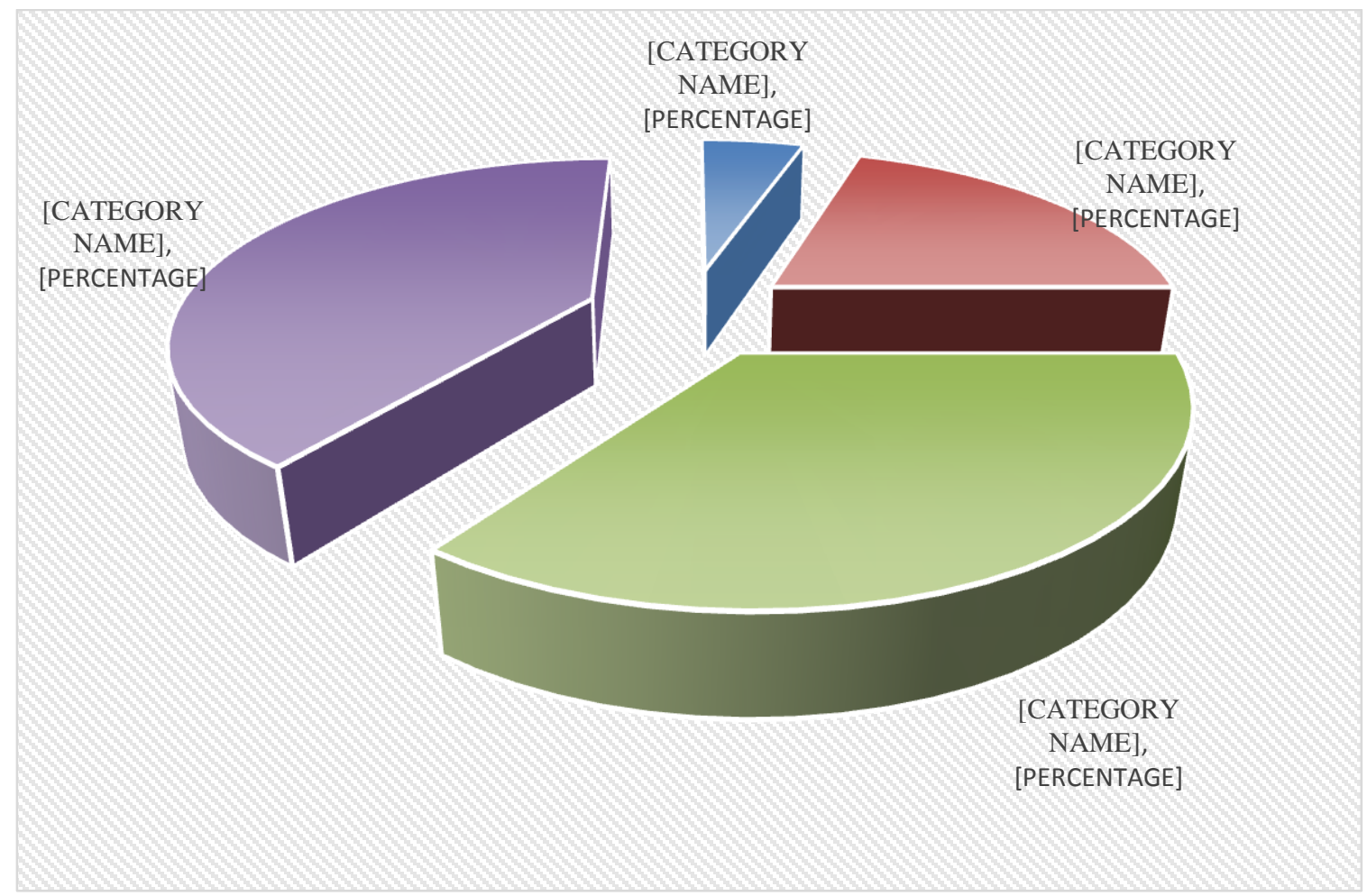

Figure 1: Frequencies distribution for years - experienced targeted groups 


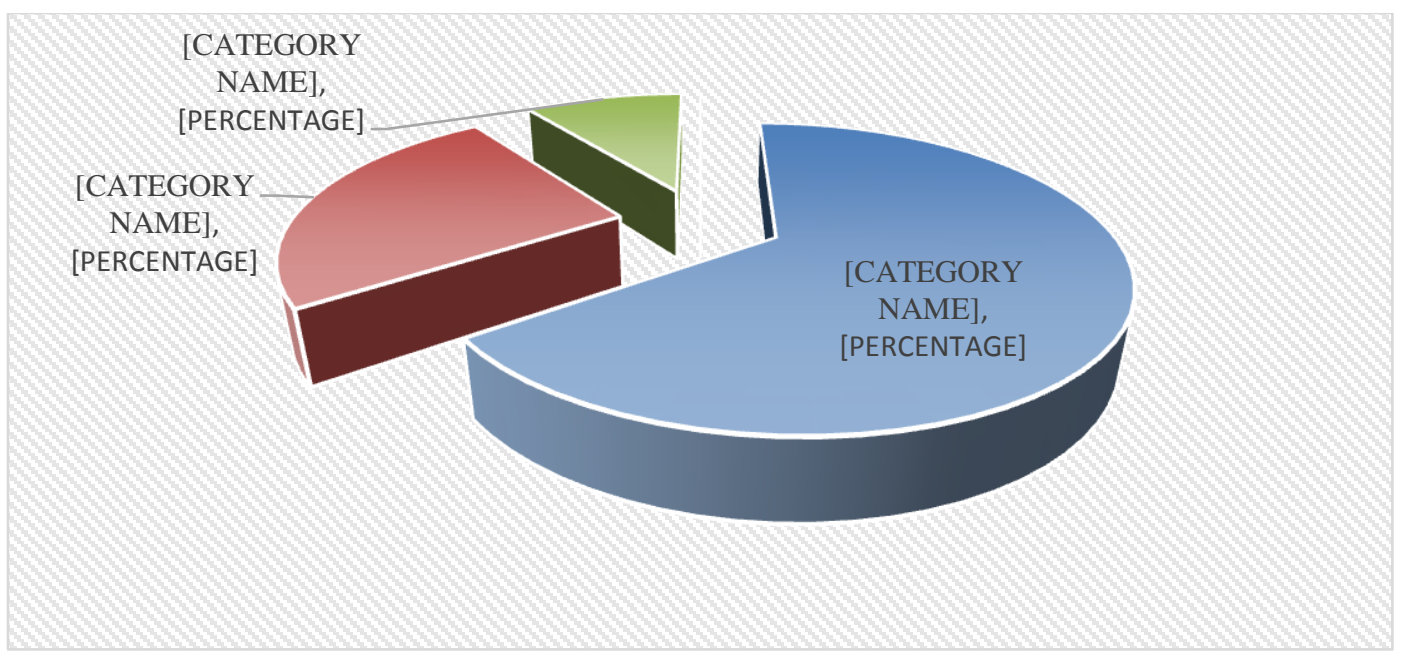

Figure 2: Frequencies distribution for education -level of targeted groups

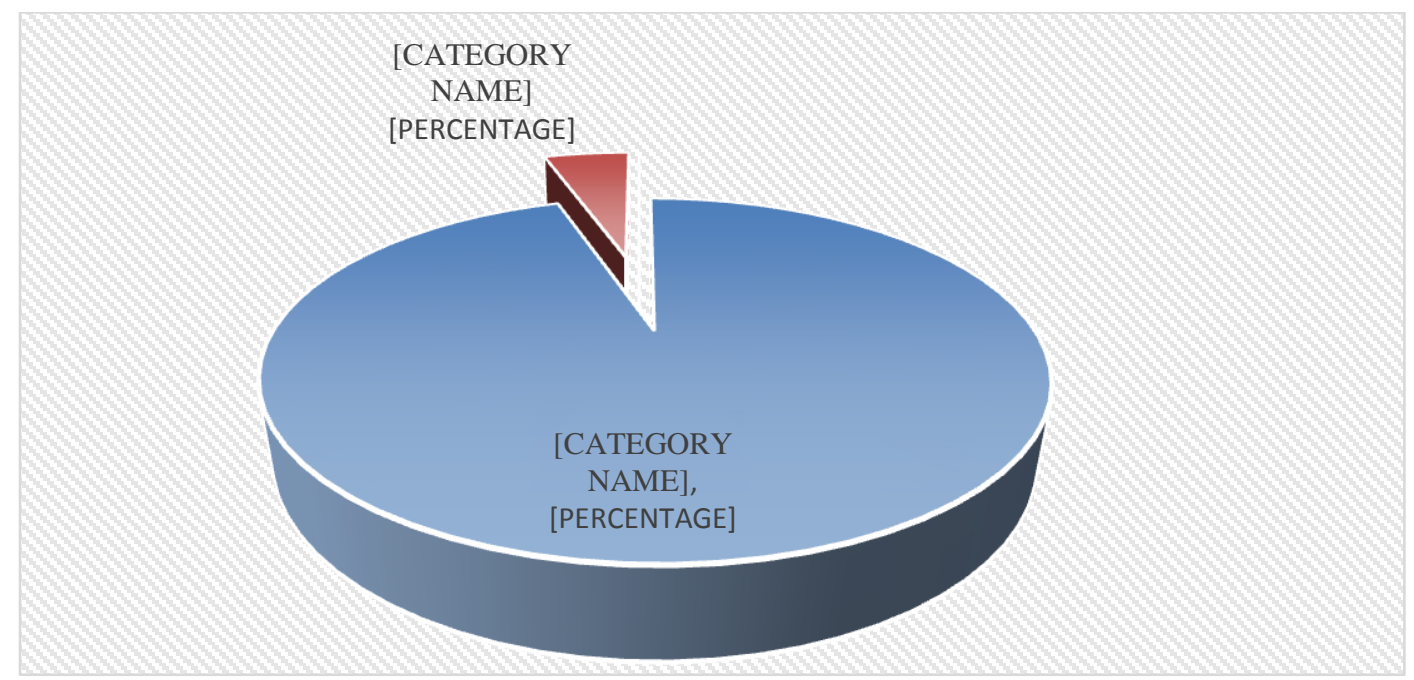

Figure 3: Field of work -targeted organizations

\subsection{The Pivot of Results for the Second Section}

This major section indicates to what extent the 12 targeted factors affect initial feasibility at the construction sector. The collected quantitative data was analyzed using a statically program (SPSS), as follows:

\subsubsection{Reliability test}

To ensure the reliability and the internal consistency for the questionnaire, it was carried out by using Cronbach's coefficient alpha $(\mathrm{C} \alpha)$. The value of $\mathrm{C} \alpha$ should be between 0 and 1 where the closer the value of one indicates that the high stability and vice versa. As shown in Table 2, it can be observed that Cronbach's alpha value for this section was $(0.984)$, which indicate a good validity and reliability of the questionnaire as the Cronbach's coefficient must exceed 0.7 .

Table 2: Reliability Statistics for 2nd section

\begin{tabular}{ll}
\hline Cronbach's Alpha & No. of Items \\
\hline 0.984 & 12 \\
\hline
\end{tabular}




\subsubsection{Analysis of results by using (AHP Model) (Analysis matrix)}

The Analytical Hierarchy Process (AHP) is a technique developed by Professor Thomas L. Saaty in (1980) as a Multi Criteria Decision Making tool, where inputs can be obtained through personal opinion such as satisfaction, or through actual measurements such as price and weight [16-19]. The main vectors are called priority vectors. The first vectors show the relative weights between the compared factors, where the sum of all factors equals one [20-22]. The AHP process involves four phases: build the decision hierarchy, determine the relative importance of factors, evaluate each alternative and calculate its overall weight in regard to each attribute, and check the consistency of the subjective evaluations [23].

In this section, each factor was measured on the Likert scale of five points as (Does not affect it, slightly affects it, directly affects it, high significance, affect it). Based on questionnaire results shown in Fig. 4, the relative weights of factors are specified by pairwise comparing the factors with respect to the goal of research; that will be found by using the AHP software program.

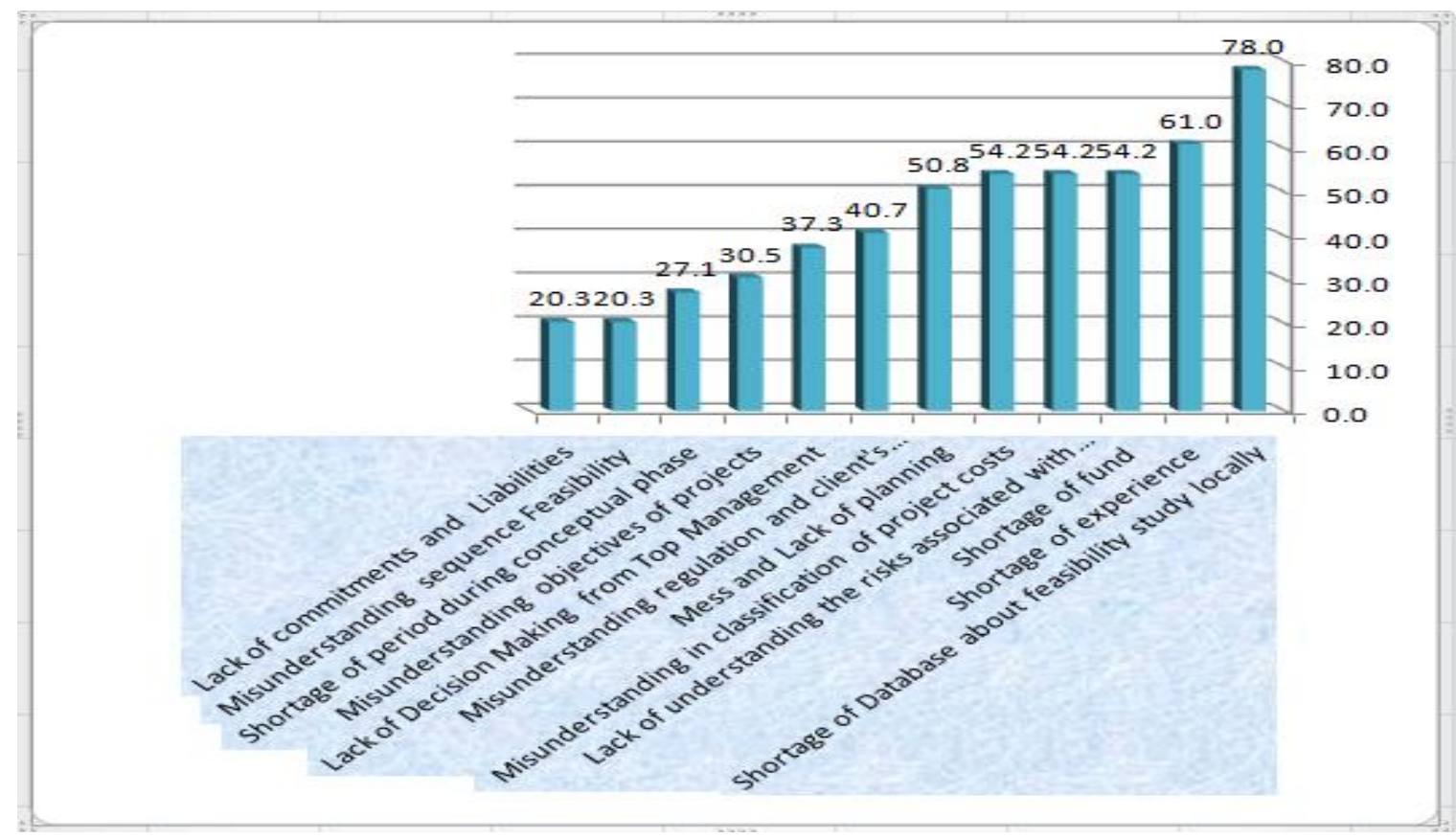

Figure 4: The \% significant impact affect of each factor on a feasibility study

Fig. 5 shows an abstract view of hierarchy distribution of the main factors with respect to the goal of research.

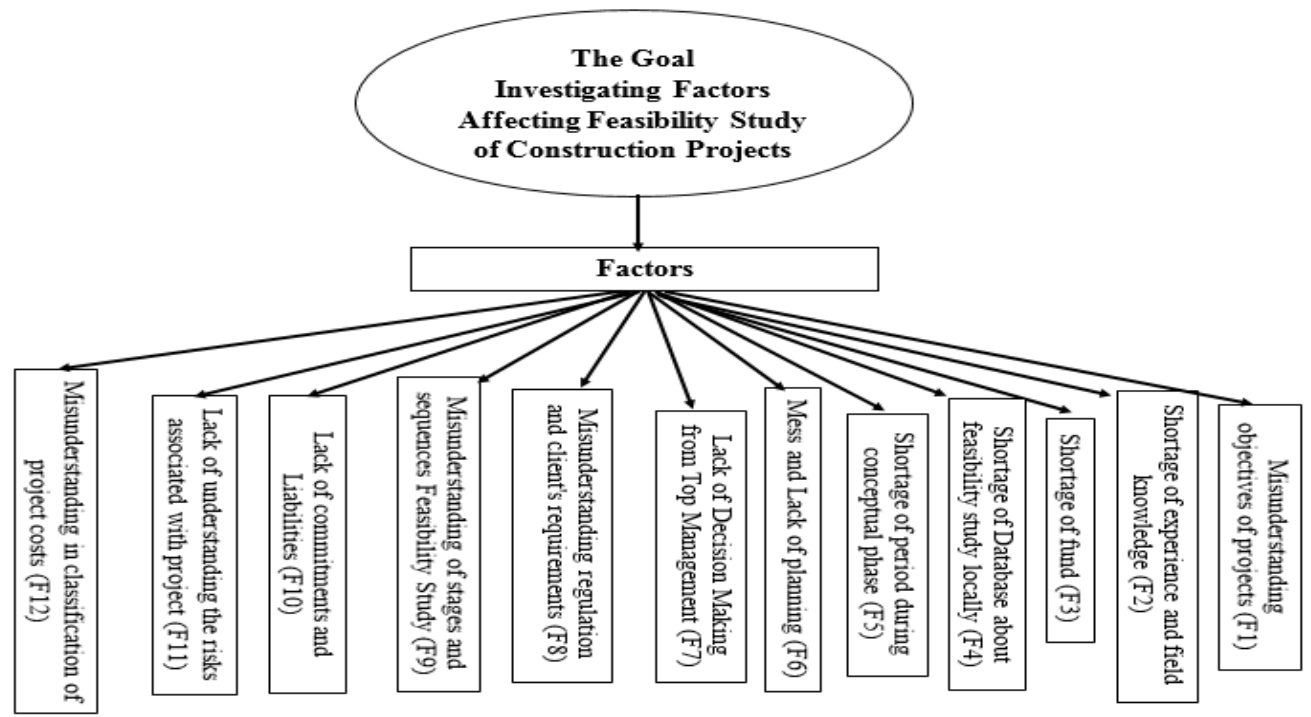

Figure 5: Hierarchy distribution of the main factors 
Fig. 6 shows the pairwise comparisons between factors with respect to the goal.

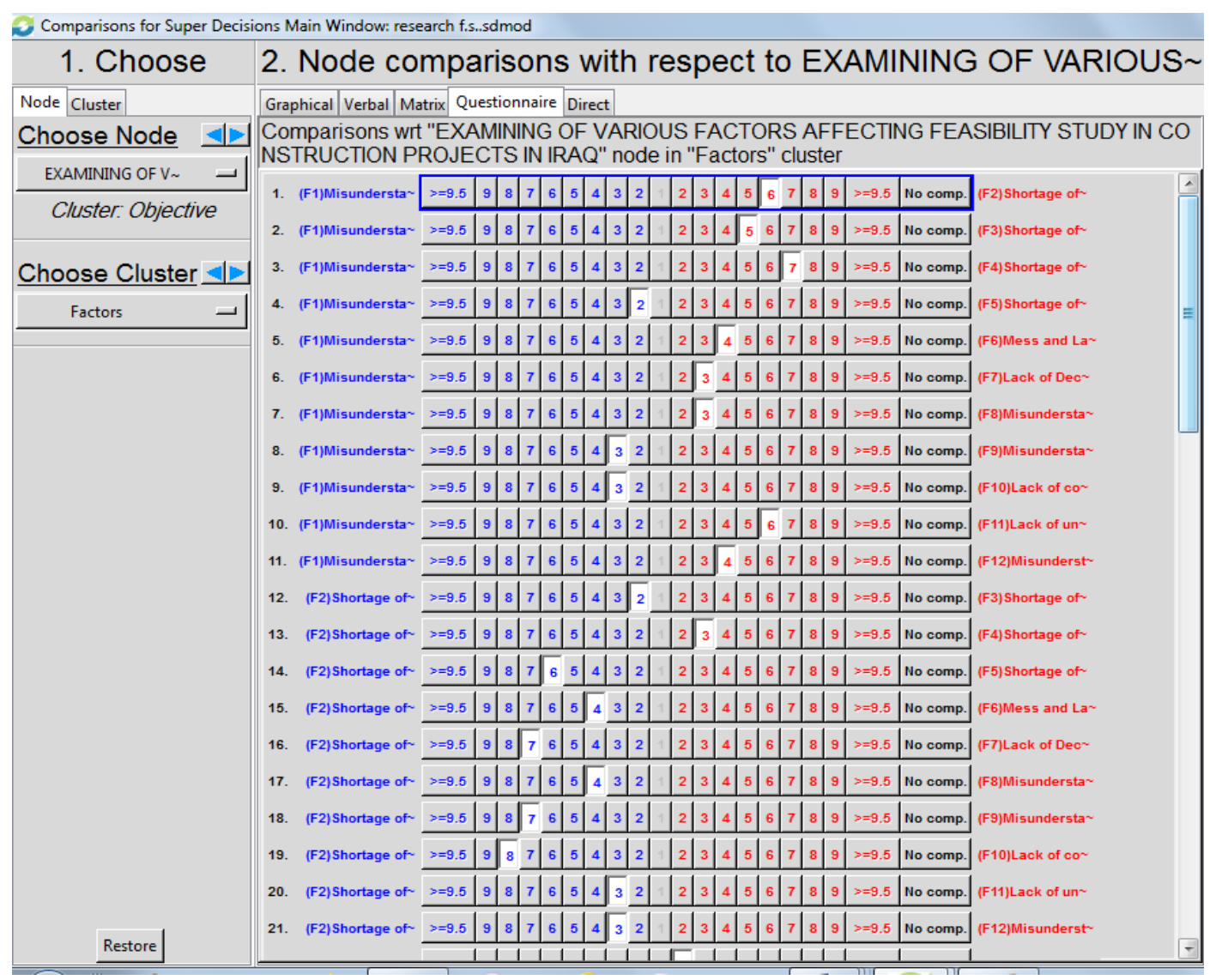

Figure 6: The pairwise comparisons between factors

The AHP program shows priorities (relative weights) of factors with respect to the goal, as shown in Fig. 7 and Table 3.

\begin{tabular}{|c|c|c|c|}
\hline 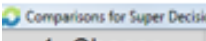 & 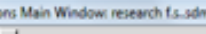 & & ㅁole $=$ \\
\hline 1. Choose & 」 & 3. Results & \\
\hline $\begin{array}{l}\text { Node Cunter } \\
\text { Choose Node }\end{array}$ & Namal -1 & Irovitencoseses & Hoted -1 \\
\hline Dowemenc ofv- - & (F1)Misun & & 0.02561 \\
\hline Chuster Objective & (F2)Short & & 0.18250 \\
\hline Choose Cluster $\leq \mid \mathrm{s}$ & (F3)Short & & 0.11096 \\
\hline & (F4)Short & & 0.25852 \\
\hline & (F5)Short & & 0.02030 \\
\hline & (F6)Mess & & 0.07049 \\
\hline & (F7)Lack & & 0.03554 \\
\hline & (F8)Misun & & 0.05340 \\
\hline & (F9)Misun & & 0.01483 \\
\hline & (F10)Lack & & 0.01361 \\
\hline & (F11)Lack & & 0.11943 \\
\hline & (F12)Misu & & 0.09482 \\
\hline sestont & & 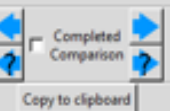 & \\
\hline
\end{tabular}

Figure 7: Weights of factors with respect to the goal 
Table 3 shows the relative weights of the twelve identified factors and their rankings.

Table 3: priorities and relative weights of factors with respect to the goal

\begin{tabular}{lll}
\hline No. & Factors (Inconsistency=0.0568) & Relative Weight (\%) \\
\hline 1 & Shortage of Database about feasibility study locally(F4) & $25.8 \%$ \\
2 & Shortage of experience and field knowledge (F2) & $18.2 \%$ \\
3 & Lack of understanding the risks associated with the project (F11) & $11.9 \%$ \\
4 & Shortage of fund (F3) & $11.1 \%$ \\
5 & Misunderstanding in the classification of project costs (F12) & $9.5 \%$ \\
6 & Mess and Lack of planning (F6) & $7.1 \%$ \\
7 & Misunderstanding regulation and client's requirements (F8) & $5.3 \%$ \\
8 & Lack of Decision Making from Top Management (F7) & $3.6 \%$ \\
9 & Misunderstanding objectives of projects (F1) & $2.6 \%$ \\
10 & Shortage of period during the conceptual phase (F5) & $2.0 \%$ \\
11 & Misunderstanding of stages and sequences Feasibility Study (F9) & $1.5 \%$ \\
12 & Lack of commitments and Liabilities (F10) & $1.4 \%$ \\
Total & & $100 \%$ \\
\hline
\end{tabular}

\subsection{The pivot of Results for the Third Section}

This minor section consists of views from the targeted people about which kind of feasibility studies is almost used it in their works to represent the decisions during the conceptual design phase of the project:

\subsubsection{Reliability test}

As shown in Table 4, it can be observed that Cronbach's alpha value for this section was (0.935), which indicate a good validity and reliability of the questionnaire for this section.

Table 4: Reliability Statistics

\begin{tabular}{ll}
\hline Cronbach's Alpha & N of Items \\
\hline 0.935 & 8 \\
\hline
\end{tabular}

\subsubsection{The Relative Importance Index (RII)}

The respondent response was then being converted into a Relative Importance Index (RII), using the following formula:

$\mathrm{RII}=\Sigma W /(H)(N)$

Where:

$\mathrm{W}=$ Total weight, given to each factor by the respondents,

$\mathrm{H}=$ Highest ranking available (i.e. 2 in this case),

$\mathrm{N}=$ Total number of responses.

Table 5 shows the relative importance index of 8 types of feasibility studies and their use rankings in the conceptual design phase of the Iraqi construction projects.

Table 5: RII ranking of feasibility studies

\begin{tabular}{|c|c|c|c|}
\hline No. & Type of study & RII & Rank \\
\hline 1 & Economic feasibility study & 0.90 & 1 \\
\hline 2 & $\begin{array}{l}\text { Environmental and social Feasibility } \\
\text { study }\end{array}$ & 0.81 & 2 \\
\hline 3 & Technical Feasibility study & 0.78 & 3 \\
\hline 4 & Market feasibility study & 0.70 & 4 \\
\hline 5 & Financial Feasibility study & 0.66 & 5 \\
\hline 6 & Schedule Feasibility study & 0.66 & 5 \\
\hline 7 & Managerial Feasibility study & 0.63 & 6 \\
\hline 8 & Legal Feasibility study & 0.63 & 6 \\
\hline
\end{tabular}


Fig. 8 shows the relative importance of use for each type of feasibility studies in the construction project.

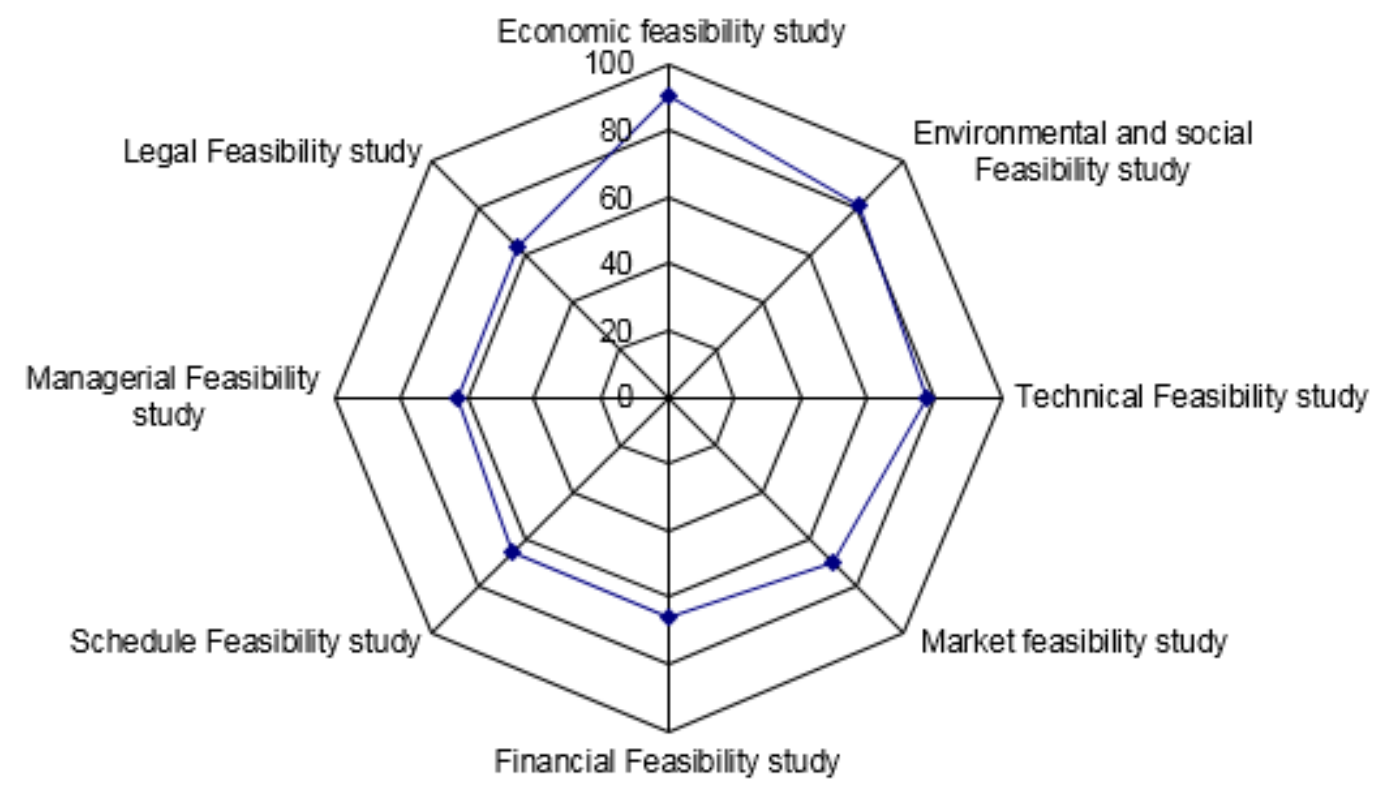

Figure 8: RII of each type of feasibility studies

\section{Conclusion}

This research has explored some critical factors that are affecting for conducting a feasibility study and then ranked them from the viewpoints of different respondent groups have significant linked and direct contact with a feasibility study.

The final outcomes of this paper through the pairwise comparing between the factors with respect to the goal of research by using the AHP software program, indicates the shortage of Database (DB) with relative weight $(25.8 \%)$, and shortage in experiences in field knowledge $(18.2 \%)$, which get the highest relative weight in making the significant impacts on initial feasibility. Those factors indicate all construction forms have to build a good historical database about their projects. In the same time, the training and field workshops are one of the important issues for staff to build their capacity and increasing their knowledge that make them overcome on all the challenge. To obtain a better benefit in any construction project that is required to put a framing to size the impacts of those factors to reduce their negative wares on the construction sector or projects. Any construction form should take valuable measures to minimize the negative impact of those factors and obtain the required feasibility studies to create more profit in their future investment in the construction sector. The views of targeted groups in the outcomes of the questionnaire give the idea that the clients or owners did not adopt all kinds of feasibility in a construction project in Iraq. The results of relative importance index of 8 types of feasibility studies also showed that the economic feasibility study is the more commonly used that others with RII $(90 \%)$.

The local construction forms have to adopt in their system all feasibility study and not only use one or two of them when they required from the local government or client. The official departments have to encourage all contractual parties to use all types of a feasibility study in professional levels and systematic ways. The client and his staff or teams have to aware exactly all the sequences of feasibility analysis and do not focus only on the economic one.

\section{References}

[1] M. Mukherjee and S. Roy, "Feasibility Studies and Important Aspect of Project Management," International Journal of Advanced Engineering and Management, vol. 2, (4), pp. 98, 2017.

[2] C. Cui et al, "Review of studies on the public-private partnerships (PPP) for infrastructure projects," International Journal of Project Management, vol. 36, (5), pp. 773-794, 2018. 
[3] R. S. Heralova, "Life Cycle Costing as an Important Contribution to Feasibility Study in Construction Projects," Procedia Engineering, vol. 196, pp. 565-570, 2017.

[4] F. M. Halil et al, "Feasibility Study and Economic Assessment in Green Building Projects," Procedia Social and Behavioral Sciences, vol. 222, pp. 56-64, 2016.

[5] G. Jia et al, "Measuring the maturity of risk management in large-scale construction projects," Automation in Construction, vol. 34, pp. 56-66, 2013.

[6] A. Abou-Zeid, A. Bushraa and M. Ezzat, "Overview of Feasibility Study Procedures for Public Construction Projects in Arab Countries," Journal of King Abdulaziz University-Engineering Sciences, vol. 18, (1), pp. 19-34, 2007.

[7] A. R. Rumane, Quality Management in Construction Projects. (2nd ed.) 2016;2017;1. DOI: 10.1201/9781315098425.

[8] M. M. Barbero-Barrera, A. J. C. Santos and M. R. Veiga, "The appearance and luminous properties of lime and gypsum pastes: A comparative analysis of different methods of measurement," Construction and Building Materials, vol. 221, pp. 562-572, 2019.

[9] J. A. Graaskamp, "A Rational Approach To Feasibility-Analysis," The Appraisal Journal, vol. 40, (4), pp. 513, 1972.

[10] M. E. Miles, Real Estate Development : Principles and Process. United States: 2000.

[11] C.B. "Bud" Johnston Library, "Business 2257 Feasibility Study," 2016.

[12] S. R. Mohammed, H. I. Naji and R. H. Ali, "Impact of the Feasibility Study on the Construction Projects," IOP Conference Series: Materials Science and Engineering, vol. 518, pp. 22074, 2019.

[13] Anonymous "Financial Feasibility Studies for Property Development: Theory and Practice," Property Management, vol. 32, (4), pp. 362-363, 2014.

[14] G. Ç. ULUBEYLİ, T. BİLİR and R. ARTIR, "Ceramic Wastes Usage as Alternative Aggregate in Mortar and Concrete," Periodicals of Engineering and Natural Sciences (PEN), vol. 5, (2), 2017.

[15] G. Rey et al, "Performance analysis, model development and validation with experimental data of an ICE-based micro-CCHP system," Applied Thermal Engineering, vol. 76, pp. 233-244, 2015.

[16] K. Cao et al, "Lifetime-aware real-time task scheduling on fault-tolerant mixed-criticality embedded systems," Future Generation Computer Systems, vol. 100, pp. 165-175, 2019.

[17] S. Ulubeyli, A. Kazaz and V. Arslan, "A Structured Selection Process for Small and Medium Enterprises in Construction Industry: Case of International Projects," Periodicals of Engineering and Natural Sciences (PEN), vol. 5, (3), 2017.

[18] M. Karabulut, "Application of Monte Carlo simulation and PERT/CPM techniques in planning of construction projects: A Case Study," Periodicals of Engineering and Natural Sciences (PEN), vol. 5, (3), 2017.

[19] B. Durakovic and H. Basic, "Continuous Quality Improvement in Textile Processing by Statistical Process Control Tools: A Case Study of Medium-Sized Company," Periodicals of Engineering and Natural Sciences, vol. 1, no. 1, pp. 39-46, 2013.

[20] B. Durakovic, "Design of Experiments Application, Concepts, Examples: State of the Art," Periodicals of Engineering and Natural Scinces, vol. 5, no. 3, p. 421-439, 2017.

[21] M. Hanine et al, "A new integrated methodology using modified Delphi-fuzzy AHP-PROMETHEE for Geospatial Business Intelligence selection," Information Systems and e-Business Management, vol. 15, (4), pp. 897-925, 2017.

[22] A. Soltani and E. Z. Marandi, "HOSPITAL SITE SELECTION USING TWO-STAGE FUZZY MULTICRITERIA DECISION MAKING PROCESS," Journal of Urban and Environmental Engineering, vol. 5, (1), pp. 32-43, 2011.

[23] P. Usta, "Sustainability of Traditional Buildings Located in Rural Area," Periodicals of Engineering and Natural Sciences (PEN), vol. 5, (2), 2017. 